LBNL-60290

MICE PUB GEN 155

\title{
Does One Know the Properties of a MICE Solid or Liquid Absorber to Better than 0.3 Percent?
}

\author{
Michael A. Green ${ }^{\mathrm{a}}$ and Stephanie Q. Yang \\ a) Lawrence Berkeley National Laboratory, Berkeley CA 94720, USA \\ b) Oxford University Physics Department, Oxford OX1-3RH, UK
}

20 February 2006*

* This work was supported by the Oxford University Physics Department and the Particle Physics and Astronomy Research Council of the United Kingdom. This work was also supported by the Office of Science, United States Department of Energy, under DOE contract DE-AC02-05CH11231. DOE funding for the US Neutrino Factory and Muon Collider Collaboration is gratefully acknowledged. 
LBNL-60290

MICE PUB GEN xxx

\title{
Does One Know the Properties of a MICE Solid or Liquid Absorber be to Better than 0.3 Percent?
}

\author{
Michael A. Green ${ }^{\mathrm{a}}$ and Stephanie Q. Yang \\ a) Lawrence Berkeley National Laboratory, Berkeley CA 94720, USA \\ b) Oxford University Physics Department, Oxford OX1-3RH, UK
}

20 February 2006*

\begin{abstract}
This report discusses the report discusses whether the MICE absorbers can be characterized to \pm 0.3 percent, so that one predict absorber ionization cooling within the absorber. This report shows that most solid absorbers can be characterized to much better than \pm 0.3 percent. The two issues that dominate the characterization of the liquid cryogen absorbers are the dimensions of the liquid in the vessel and the density of the cryogenic liquid. The thickness of the window also plays a role. This report will show that a liquid hydrogen absorber can be characterized to better than \pm 0.3 percent, but a liquid helium absorber cannot be characterized to better and \pm 1 percent.
\end{abstract}

\section{TABLE OF CONTENTS}

\author{
Abstract \\ Introduction to Ionization Cooling and the MICE Absorbers \\ Accuracy of the Prediction of Performance for MICE Solid Absorbers \\ Liquid Absorbers, Prediction of the Dimensions and the Liquid Volume \\ Liquid Absorbers, Prediction of the Density of the Fluid in the Absorber \\ The Thin Windows and their Effect on Absorber Performance \\ Concluding Comments \\ Acknowledgements \\ References \\ * Last revision 26 November 2006
}

Page

1.

2.

4.

5 .

10.

13.

16.

17.

17. 


\section{Introduction to Ionization Cooling and the MICE absorbers}

The key to cooling muons (reducing their emittance) within their lifetime (2.1 $\square$ s at rest) is to use ionization cooling [1]. Ionization cooling has been selected as a cooling method, because stochastic cooling, electron cooling and laser cooling take a long time $(>1 \mathrm{sec})$ compared to the life of a muon. When a muon enters a material, energy is lost along the track. This means that both longitudinal and transverse momentum is lost as the muon passes through the cooling material. If the muon is re-accelerated in the longitudinal direction, the loss of transverse momentum is retained and beam cooling has been achieved. Coulomb scattering of the muon beam in the material counters the effect of cooling. If the emittance lost is greater than emittance gained due to scattering, net ionization cooling results.

An equation that describes ionization cooling can be stated as follows [2]:

$$
\frac{d \square_{x, N}}{d z}=\square \frac{1}{\square^{2}} \frac{\square_{x, N}}{E}=\frac{\square d E}{\square d z} \boxminus+\square_{\square} \frac{(0.014 G e V)^{2}}{2 \square^{3} E m_{\square} L_{R}}
$$

where $\square_{k, N}$ is the muon emittance; $\square=v / c ; E$ is the muon energy; $\square_{\square}$ is the transverse beam beta, $m_{\square}$ is the mass of a muon and $L_{R}$ is the radiation length of the absorber.

The term with the minus sign on the right hand side of Equation 1 is the cooling term; the term on the right hand side of Equation 1 with the plus sign is the coulomb scattering term. For rapid ionization cooling one needs strong focusing in order to achieve a low value of $\square_{\square}$ and on wants to have a high value of $L_{R}$, which implies that one wants to use a low Z material for doing the cooling. In general, cooling is proportional to the number of electrons in the atom. Coulomb scattering is proportional to the number of charged nucleons in the atom squared. Thus hydrogen is the best material to use for ionization cooling. Table 1 compares the properties of a number of liquid and solid absorbers.

Table 1. A Comparison of the Properties of Various Absorber Materials

\begin{tabular}{|c|c|c|c|c|c|}
\hline Absorber Material & $\begin{array}{c}\mathbf{d E} / \mathbf{d x} \\
\left(\mathrm{MeV} \mathrm{g}^{-1} \mathrm{~cm}^{2}\right)\end{array}$ & $\begin{array}{c}\mathbf{L}_{\mathbf{R}} \\
\left(\mathrm{g} \mathrm{cm}^{-2}\right)\end{array}$ & $\begin{array}{c}\text { Density } \\
\left(\mathrm{g} \mathrm{cm}^{-3}\right)\end{array}$ & $\begin{array}{c}\text { L for 10 MeV } \\
\text { of Absorption } \\
(\mathrm{cm})\end{array}$ & $\begin{array}{c}\text { Equilibrium } \\
\text { Cooling } \\
\text { Factor }\end{array}$ \\
\hline Liquid Hydrogen (20.3 K) & 4.12 & 61.3 & 0.07078 & 34.28 & 1.000 \\
\hline Liquid Helium (4.22 K) & 1.94 & 94.3 & 0.1249 & 41.24 & 0.524 \\
\hline Lithium Hydride & 1.89 & 79.3 & $\sim 0.78$ & $\sim 6.8$ & $\sim 0.35$ \\
\hline Lithium & 1.65 & 82.8 & 0.534 & 11.35 & 0.268 \\
\hline Beryllium & 1.61 & 85.2 & 1.848 & 3.361 & 0.172 \\
\hline Polystyrene (CH) & 2.09 & 43.3 & 1.032 & 4.636 & $\sim 0.15$ \\
\hline Carbon (graphite) & 1.78 & 42.7 & 1.8 to 2.3 & 2.4 to 3.1 & $\sim 0.13$ \\
\hline 1100-Aluminum & 1.62 & 24.3 & 2.699 & 2.287 & $\sim 0.05$ \\
\hline
\end{tabular}

Table 1 compares various liquid and solid materials that can be used for muon ionization cooling. The last column in Table 1 compares the relative emittance reduction to the equilibrium value (the value where coulomb scatting exactly matches the cooling term). From Table 1, one can see that hydrogen should be twice as good as any other cooling material. This is not completely true because liquid hydrogen must in a leak tight container. Helium must also be contained. The container windows will reduce the relative performance of the two liquids. 
The muon ionization cooling experiment (MICE) absorbers are located in the center of the MICE absorber focus coil (AFC) modules [3]. For operation of MICE in the flip and the nonflip mode, the centers of the AFC modules represent the low $\square_{b}$ points for the cooling channel. Cooling is maximized because the absorbers are located in the center of the AFC modules. When the MICE channel is operated with liquid absorbers, the absorbers are nominally $0.35 \mathrm{~m}$ $(350 \mathrm{~mm})$ thick at their center [4]. The MICE is designed to operate with either liquid hydrogen or liquid helium in the liquid absorbers. When there is hydrogen in the absorber, most of the muons will have $\sim 10.2 \mathrm{MeV}$ of energy removed from them by the absorber. When the absorber is filled with liquid helium, the energy reduction for most of the muons is $\sim 8.5 \mathrm{MeV}$.

The MICE channel is designed so that the liquid absorbers can be removed and be replaced by solid absorbers made from various materials. (See Table 1 for candidate solid absorber materials.) The solid absorbers will operate at room temperature. Since MICE muon beam intensity is low, there will be no appreciable heating of the solid absorbers by the beam. Any heating due to muon cooling or radiation absorption from the cavities can be removed from the solid absorbers by thermal radiation. The temperature rise in the absorber is minimal.

Figure 1 below shows a schematic representation of the AFC module with a liquid absorber. When a solid absorber is installed, the liquid absorber is removed and the solid absorber goes into middle of the magnet in the space between the two superconducting coils [5].

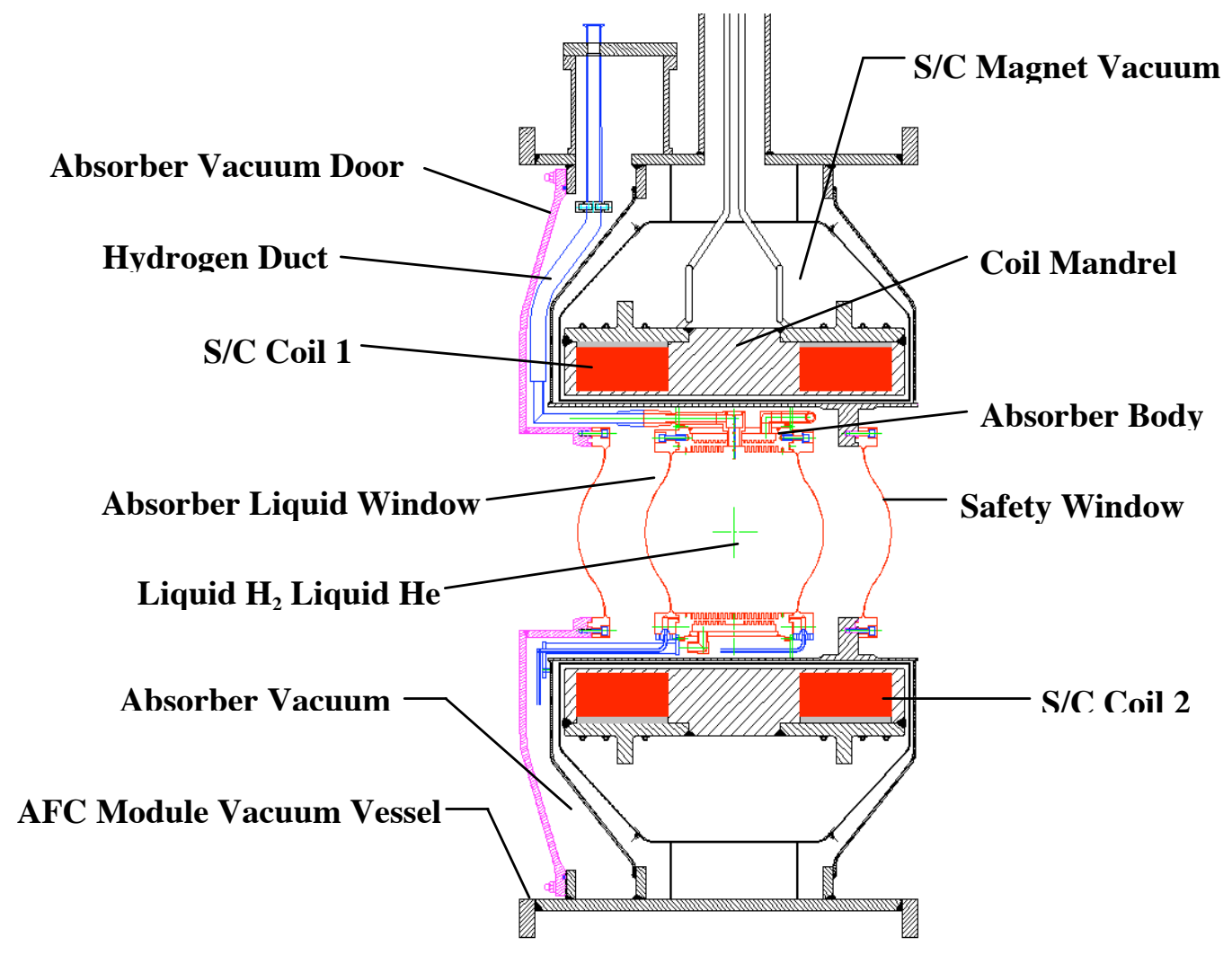

Figure 1. The liquid absorber within the AFC module. The center of the absorber corresponds to the center of the AFC superconducting magnet. This is where $\square_{\square}$ is lowest. 


\section{Accuracy of the Prediction of Performance for MICE Solid Absorbers}

In the early stages of the experiment, MICE will use solid absorbers. The absorber focus coil module (AFC module) is designed so that the liquid absorber (liquid hydrogen or liquid helium) can be removed and be replaced by a solid absorber. The end plate for the AFC module, which contains a safety window, is removed. Then four pipes that connect the absorber to the cooling system are disconnected. The liquid absorber is removed and replaced with a solid absorber. The AFC module end plate may or may not be put back into position. Whether the end plate must be installed depends on whether out-gassing from the absorber affects the performance of the adjacent RF cavity. The properties of candidate solid absorbers are discussed in the paragraphs that follow [2], [6], [7], [8].

Lithium Hydride: Lithium hydride is theoretically the best material to use as a solid absorber. The reason that lithium hydride is considered to be the best solid absorber is that it has fewer neutrons than any of the solid. The density of lithium hydride is about $780 \mathrm{~kg} \mathrm{~m}^{-3}$. The problem with lithium hydride is that is rarely can be found in the pure state. Lithium hydride is usually contaminated with lithium hydroxide. Most of the lithium hydride produced is in granular form. The melting temperature for lithium hydride is $620 \mathrm{C}$, but it decomposes at a temperature of about $700 \mathrm{C}$. Pure melt cast lithium hydride is difficult to come by. Because lithium hydride reacts with water in the air, lithium hydride must be in a container. The obvious container material is aluminum, but lithium hydride will react with aluminum to produce lithiumaluminum hydride. While lithium hydride is still a candidate material for solid absorbers, it may not be suitable for MICE because its density is probably not uniform to \pm 1 percent. With the proper container, the dimensions of a lithium hydride absorber can be fabricated to $\pm 0.2 \mathrm{~mm}$.

Lithium: Lithium is the second best solid absorber material. Lithium is a reactive metal that reacts with water in the air. Lithium has a melting temperature of $425 \mathrm{C}$. It appears that lithium can be melt cast into a container in an inert atmosphere. Lithium will alloy with aluminum, but aluminum is a viable container material for solid lithium. Lithium can be obtained in relatively pure form, so it is probable that the density of a lithium absorber (534 $\mathrm{kg}$ $\mathrm{m}^{-3}$ ) is uniform to better than \pm 0.3 percent. With the proper container, the dimensions of a lithium absorber can be fabricated to $\pm 0.2 \mathrm{~mm}$. Lithium is a viable absorber material, but it is not the easiest absorber material to use in MICE or an absorber for cooling muons in a neutrino factory or a muon collider. Lithium can probably be characterized to \pm 0.3 percent

Beryllium: Beryllium is not as good an absorber as either lithium hydride or lithium. Beryllium can be fabricated and machined by a qualified beryllium vendor. Beryllium is poisonous, but as a large solid it is relatively inert and can be handled. Pure beryllium has a density of $1848 \mathrm{~kg} \mathrm{~m}^{-3}$. Beryllium can be machined (by a certified vendor) to an accuracy of better than $0.025 \mathrm{~mm}$ (0.001 inch). Beryllium is a suitable absorber for MICE, because it can be characterized to better than \pm 0.07 percent.

Plastics: There are a number of candidate plastics that can be used as absorbers for MICE. The best plastics are predominately one part carbon and two parts hydrogen. Two are polystyrene and polyethylene. Both have similar $\mathrm{dE} / \mathrm{dx}$ and equilibrium cooling factors. Polystyrene is the best candidate because its density is very uniform over the sample. Polyethylene exists in a couple of forms, so its density is more variable. For a given sample, the density of polyethylene is quite uniform. Polystyrene can be machined to within 0.010 to 0.015 $\mathrm{mm}$. Polyethylene does not machine as well. Polystyrene can be characterized to \pm 0.05 percent, but polyethylene is not as good in terms of its characterization. Neither plastic is suitable for use in a neutrino-factory cooling channel. 
Carbon is the form of graphite is a reasonably good choice for a solid absorber. Graphite has a wide range of densities, but any given sample as reasonably good uniformity in density (of the order of \pm 0.1 to 0.2 percent. Graphite can be machined with reasonably good accuracy. Graphite probably can be characterized to better than \pm 0.3 percent.

Metals such as magnesium and aluminum have similar $\mathrm{dE} / \mathrm{dx}$ and similar equilibrium cooling factors. Both metals machine well to \pm 0.005 to $0.007 \mathrm{~mm}$. The density of aluminum (particularly 1100 aluminum) is very uniform. Magnesium alloys are quite uniform in their density as well. One can expect aluminum to be characterized to about \pm 0.05 percent.

The solid absorbers that appear to be the most viable for use in MICE are beryllium, polystyrene, magnesium or aluminum. All of these absorber materials can be characterized to better \pm 0.1 percent. In terms of cost, these materials are cost effective as well.

\section{Liquid Absorbers, Prediction of the Dimensions and the Liquid Volume}

The characterization of the liquid absorber is dependent on three factors. These factors are: 1) prediction of the absorber dimensions at the operating temperature and pressure, 2) the prediction of the density of the fluid in the absorber, and 3) the prediction of the effect of the thin windows on absorber performance. This section of this report shows how one can predict the position of the fluid boundary as a function of absorber temperature and pressure. The next two sections deal with the prediction of the fluid density and the prediction of the effects of the thin windows on absorber performance.

\section{The effect of Temperature on the Liquid Boundary}

The liquid absorber is filled with liquid hydrogen $(20.3 \mathrm{~K})$ or liquid helium $(4.22 \mathrm{~K})$. The absorber shrinks as it cools down to the operating temperature. At liquid nitrogen temperature $(77.3 \mathrm{~K})$, about ninety percent of the shrinkage occurs. By the time the absorber reaches $20 \mathrm{~K}$, virtually all of the shrinkage has already occurred. The shrinkage of the absorber due to its cool down can be represented by the following expression;

$$
L_{c}=L_{w}(1 \square \square)
$$

where $L_{w}$ is the dimension of the absorber at the warm temperature $T_{w} ; L_{c}$ is the dimension of the absorber at the operating temperature $T_{w}$; and $\square$ is the total contraction coefficient for the aluminum in the absorber body. An expression for $\square$ for 6061-aluminum is given as follows [9];

$$
\square=0.0037+0.0000025\left(T_{w} \square 273.16\right)
$$

The volume of the absorber $V_{c}$ at temperature $T_{c}$ can be calculated from the volume of the absorber $V_{w}$ at temperature $T_{w}$ using the following expression;

$$
V_{c}=V_{w}(1 \square \square)^{3}
$$

When the aluminum absorber temperature is reduced from $20 \mathrm{C}(293.16 \mathrm{~K}$ ) to $20 \mathrm{~K}$ (or $4 \mathrm{~K}$ ), the shrinkage of the linear dimensions is 0.425 percent. The shrinkage of the absorber volume during a cool down from $20 \mathrm{C}(293.16 \mathrm{~K})$ to $20 \mathrm{~K}$ is 1.270 percent. The shrinkage of the absorber occurs before the absorber is filled with liquid. At $20 \mathrm{C}$ the MICE absorber volume is 20.69 liters. When the absorber is filled with liquid (at $20 \mathrm{~K}$ or $4.2 \mathrm{~K}$ ), its volume is 20.43 liters. The absorber liquid length is reduced from $350 \mathrm{~mm}$ to $348.51 \mathrm{~mm}$ (at the center of the absorber). 


\section{The effect of pressure on the liquid Boundary}

The liquid absorber dimensions are also affected by the pressure difference between the absorber volume and the absorber vacuum volume. Pressure affects the dimensions of the absorber body, and it causes deflection of the thin windows. The pressure in the absorber can change depending on the operating temperature while the absorber is filled with liquid cryogens. Figure 2 shows the vapor pressure of para hydrogen as a function of temperature [7], [10]. Figure 3 show the vapor pressure of helium as a function of temperature [11].

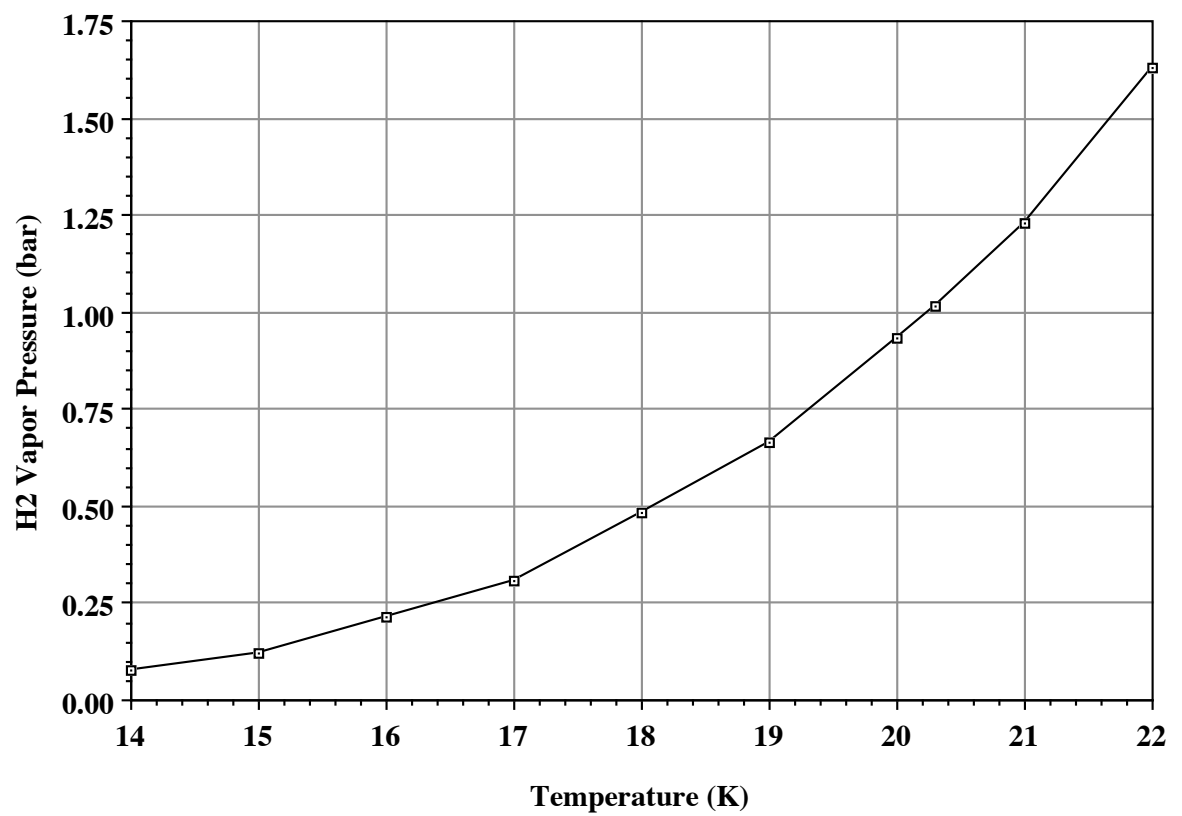

Figure 2. The vapor pressure of liquid para hydrogen as a function of temperature from $14 \mathrm{~K}$ to $22 \mathrm{~K}$. (Note: the triple point temperature for para hydrogen is $13.92 \mathrm{~K}$.)

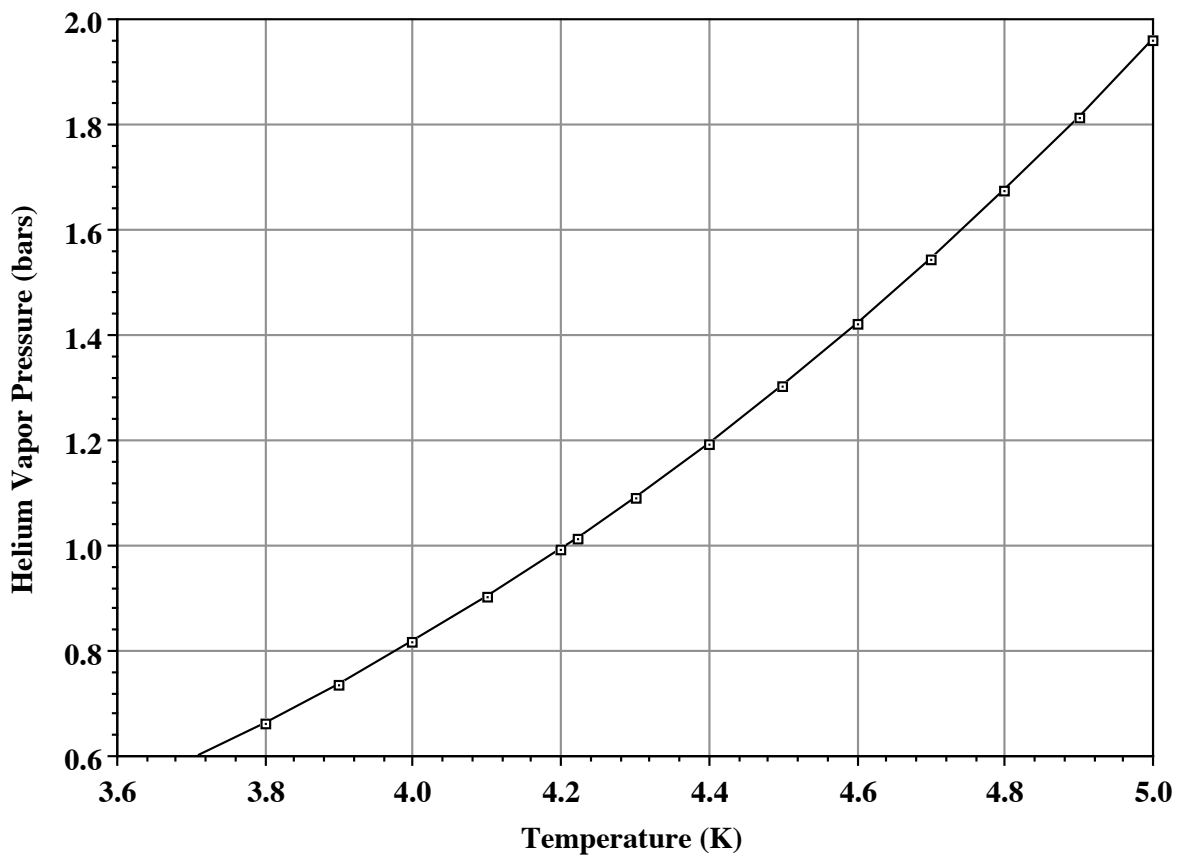

Figure 3. The vapor pressure of liquid helium as a function of temperature from $3.6 \mathrm{~K}$ to $5 \mathrm{~K}$. 
If the absorber is operated with its para hydrogen at its vapor pressure (above its triple point temperature of $13.92 \mathrm{~K}$ ), the pressure can vary from 0.07 bars to 1.6 bars (the relief valve set pressure). When one is operating the absorber with hydrogen at its vapor pressure, one must control the pressure by using a heater to heat hydrogen to a set temperature. There are safety concerns (the input of air gasses through a small leak in the absorber hydrogen circuit) when the absorber is operated at a pressure lower than 1.013 bars. In order to be able to operate the absorber safely over a range of temperature and hydrogen densities, one must pressurize the liquid hydrogen in the absorber with helium gas. The most likely operating pressure for the hydrogen absorber is between 1.1 and 1.2 bar.

When the absorber is operated with helium in it, the absorber will run at the vapor pressure of the helium within it. If the net heat leak into the absorber is $1 \mathrm{~W}$, the operating temperature will be about $3.7 \mathrm{~K}$ and the operating pressure will be 0.6 bars. If the heat leak into the absorber is $2.0 \mathrm{~W}$, the operating temperature will be $4.7 \mathrm{~K}$ and the operating pressure will be 1.52 bar, which is very close to the relief pressure of the absorber relief valve.

The radial dimension change of the absorber body due to changes of pressure within the absorber can be calculated using the following expression;

$$
\square R=\stackrel{\square \square P}{\square\left[t_{\text {ave }}\right.} \underset{\square}{\square} R_{\text {ave }}^{2}
$$

where $R_{\text {ave }}$ is the average radius of the absorber body $\left(R_{\text {ave }}=0.155 \mathrm{~m}\right) ; t_{\text {ave }}$ is the average thickness of the absorber body $\left(t_{\text {ave }}=0.055 \mathrm{~m}\right) ; \square P$ is the pressure difference between the inside and the outside of the absorber $(\square P=0.12 \mathrm{MPa}$ in many cases $)$; and $E$ is the elastic modulus of the absorber body material $(E=70 \mathrm{GPa})$. The calculated value of $\square R=0.0048 \mathrm{~mm}$.

The longitudinal dimension change of the absorber body due to changes of pressure within the absorber can be calculated using the following expression;

$$
\square Z=\stackrel{\square Z_{b}}{\square} \frac{\square P}{\square R_{\text {ave }} t_{1} E}+\frac{Z_{b}}{2} \frac{\square P}{\square R_{\text {ave }} t_{2} E} \stackrel{\square}{Z_{b}}
$$

where $0 \square$ is the change in absorber body length; $Z_{b}$ is the absorber body length $\left(Z_{b}=0.220 \mathrm{~m}\right)$; $\mathrm{t}_{1}$ is the thickness of the thin portion of the heat exchanger $\left(t_{1}=0.001 \mathrm{~m}\right)$; and $t_{2}$ is the thickness of the thick portion of the heat exchanger $\left(t_{2}=0.010 \mathrm{~m}\right)$. For a pressure $\square \mathrm{P}=0.12 \mathrm{MPa}(1.2 \mathrm{bar})$, the value of $\square=0.0937 \mathrm{~mm}$.

The change in volume of the absorber body $\square V_{b}$ due to a pressure change can be calculated using the following approximate expression;

$$
\square V_{b}=\square\left[R_{b}^{2} \square Z+2 R_{b} \square R Z_{b}\right]
$$

If one does the calculation of the change in absorber body volume due to a pressure of 1.2 bars, one comes out with a volume change of $7619 \mathrm{~mm}^{3}$ or 0.00762 liters. This is a much smaller number than one would get from a change in temperature from $293 \mathrm{~K}$ to $20 \mathrm{~K}$.

The primary $\mathrm{z}$ direction deflection and change in the absorber volume is due to the deflection of the absorber thin windows. The deflection is approximately linear with pressure up to the point the window yields (at about 2 bar internal pressure). The deflection of the windows due to internal pressure was calculated using ANSYS [12]. 
Figure 4 show the deflection of the thin $300 \mathrm{~mm}$ diameter thin windows as a function of pressure and window radius. At $r=150 \mathrm{~mm}$, the window is tied to a stiff support ring. This ring is attached directly to the body of the absorber. The ring itself deflects with the absorber body.

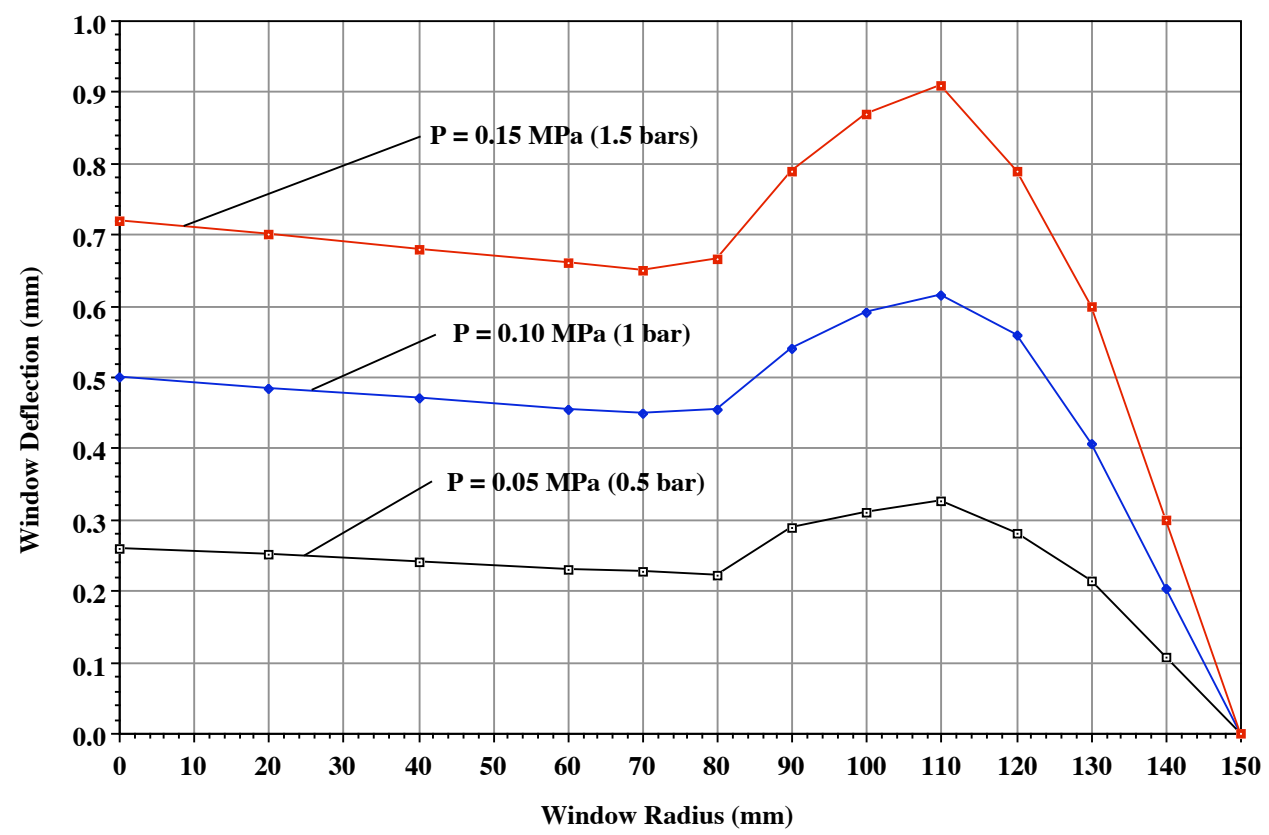

Figure 4. The absorber window deflection (in the $\mathrm{Z}$ direction) as a function of pressure from 0 to 1.5 bars.

One can see from Figure 4 that the $\mathrm{z}$ direction defection of the thin windows is much larger than the $\mathrm{z}$ direction deflection of the absorber body. What is interesting is that the peak deflection with pressure occurs at about $r=110 \mathrm{~mm}$. This is the point where there is an inflection point in the bellows window curvature. The center of the window deflects under pressure slightly more than a point at $r=80 \mathrm{~mm}$. As one can see from Figure the deflection of the window is almost linear with pressure. At $\square \mathrm{P}=0.12 \mathrm{MPa}(1.2 \mathrm{bar})$, the center of the window deflects into the absorber vacuum space about $0.6 \mathrm{~mm}$. The absorber body deflection is only about $0.047 \mathrm{~mm}$.

The change in volume due to pressure is primarily in the window deflection. An expression for the volume change for both absorber windows $\square V_{w}$ when subjected to a pressure change $\square P$ is as follows;

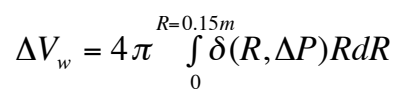

The total volume change in the absorber $\square V_{a}$ due to an absorber pressure change $\square P$ can be calculated using the following expression;

$$
\square V_{a}=\square V_{b}+\square V_{W}
$$

For a $\square \mathrm{P}=0.12 \mathrm{MPa}(1.2 \mathrm{bar})$, the change in the volume in the windows is 0.0659 liters. The total volume change due to a $\square \mathrm{P}=0.12 \mathrm{MPa}$ (1.2 bar) is 0.0735 liters. This volume change will occur before the absorber is filled with liquid. The total volume change due to pressure is about 25 percent of the change in volume due to the cool down from $293 \mathrm{~K}$ to $20 \mathrm{~K}$. 
The change in the liquid volume is very predictable provided one knows the temperature and pressure in the absorber. Table 2 shows the position of the liquid boundary in terms of $r$ and $\mathrm{z}$ as a function of temperature at zero pressure and 1.2 bars. The $\mathrm{r}=0$ and $\mathrm{z}=0$ values are from the center of the absorber.

Table 2. The $\mathrm{r}$ and $\mathrm{z}$ Coordinates of the Liquid Boundary at $293 \mathrm{~K}$ and $20 \mathrm{~K}$ at $\mathrm{P}=0$ and $\mathrm{P}=1.2 \mathrm{bar}$ (at $20 \mathrm{~K}$ )

\begin{tabular}{|c|c|c|c|c|}
\hline \multicolumn{2}{|c|}{ Absorber $\mathrm{T}=293.16 \mathrm{~K}$} & \multicolumn{3}{|c|}{ Absorber $\mathrm{T}=20 \mathrm{~K}($ or $4 \mathrm{~K})$} \\
\hline $\mathrm{R}$ at $\mathrm{P}=0(\mathrm{~mm})$ & $\mathrm{Z}$ at $\mathrm{P}=0(\mathrm{~mm})$ & $\mathrm{R}$ at $\mathrm{P}=0(\mathrm{~mm})$ & $\mathrm{Z}$ at $\mathrm{P}=0(\mathrm{~mm})$ & $\mathrm{Z}$ at $\mathrm{P}=1.2 \mathrm{~b}(\mathrm{~mm})$ \\
\hline 0 & 175.000 & 0 & 174.266 & 174.844 \\
\hline 10 & 174.642 & 9.956 & 173.909 & 174.484 \\
\hline 20 & 173.564 & 19.912 & 172.800 & 173.370 \\
\hline 30 & 171.748 & 29.868 & 170.992 & 171.558 \\
\hline 40 & 169.164 & 39.824 & 168.419 & 168.981 \\
\hline 50 & 165.767 & 49.780 & 165.376 & 165.934 \\
\hline 60 & 161.491 & 59.736 & 160.780 & 161.334 \\
\hline 70 & 156.244 & 69.692 & 155.557 & 156.105 \\
\hline 80 & 149.891 & 79.648 & 149.231 & 149.780 \\
\hline 90 & 142.422 & 89.604 & 141.975 & 142.473 \\
\hline 100 & 136.011 & 99.560 & 135.413 & 136.137 \\
\hline 110 & 131.090 & 109.516 & 130.513 & 131.273 \\
\hline 120 & 127.434 & 119.472 & 126.873 & 127.623 \\
\hline 130 & 124.904 & 129.428 & 124.355 & 124.835 \\
\hline 140 & 123.417 & 139.384 & 122.874 & 123.114 \\
\hline 150 & 122.926 & 149.340 & 122.385 & 122.385 \\
\hline
\end{tabular}

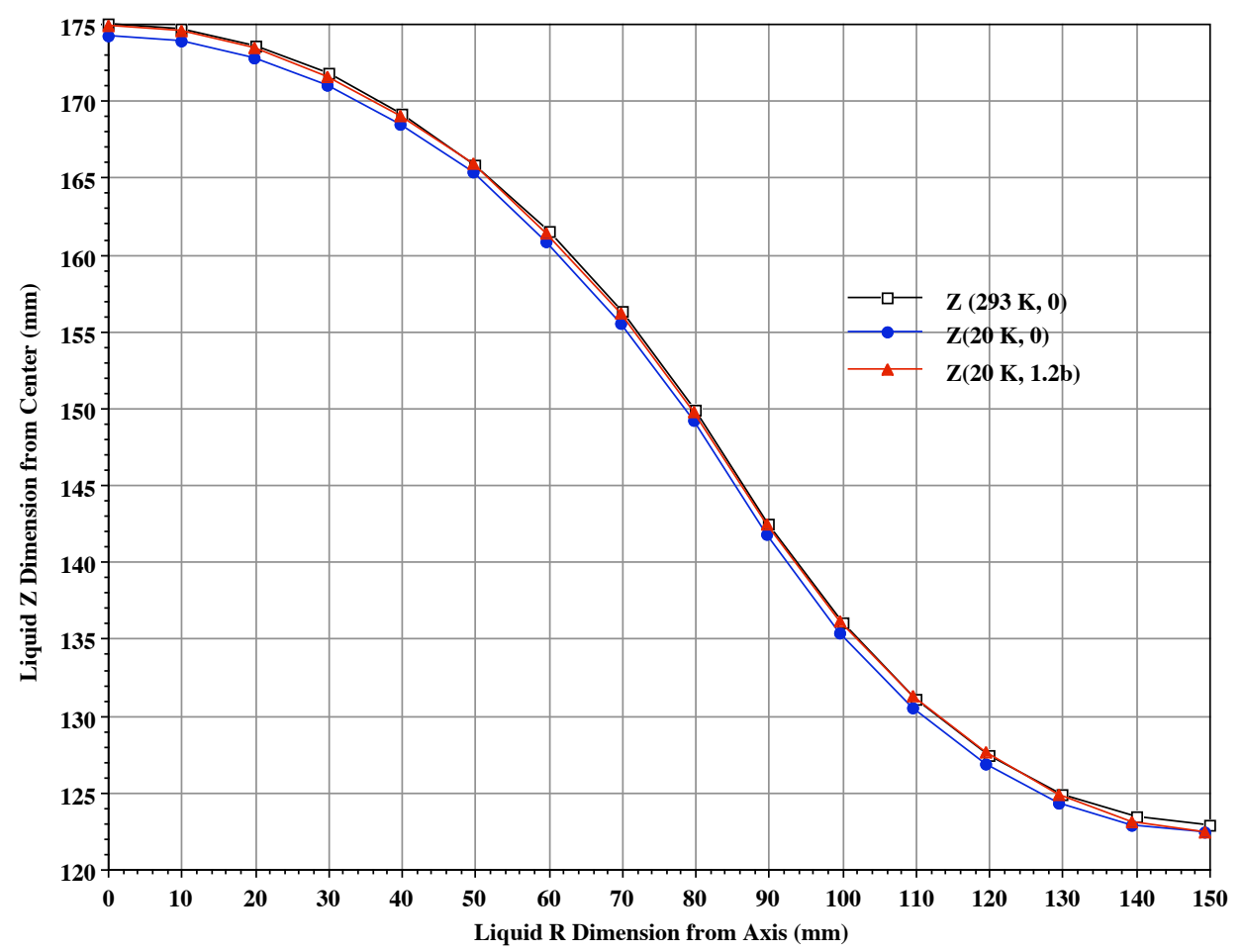

Figure 5. The $\mathrm{Z}$ position of the inner wall of the absorber window (from the absorber center) from $\mathrm{R}=0$ to $\mathrm{R}=150$ $\mathrm{mm}$. The cases are $\mathrm{T}=293 \mathrm{~K}, \mathrm{P}=0 ; \mathrm{T}=20 \mathrm{~K}, \mathrm{P}=0$, and $\mathrm{T}=20 \mathrm{~K}, \mathrm{P}=1.2 \mathrm{bar}$. 
Figure 5 shows the $\mathrm{r}$ and $\mathrm{z}$ location of the inside of the absorber at $\mathrm{T}=293 \mathrm{~K}(20 \mathrm{C})$. Also shown in Figure 5 is the $\mathrm{r}$ and $\mathrm{z}$ location of the liquid boundary at $\mathrm{T}=20 \mathrm{~K}$ (or 4.2 ) at zero pressure and an internal pressure of $0.12 \mathrm{MPa}(1.2 \mathrm{bars})$. Figure 6 shows a magnified view of Figure 5 in the center of the absorber from $r=0$ to $r=60 \mathrm{~mm}$. Seventy-five to eighty percent of the muons being cooled by MICE will enter the absorber at a radius that is less than $60 \mathrm{~mm}$.

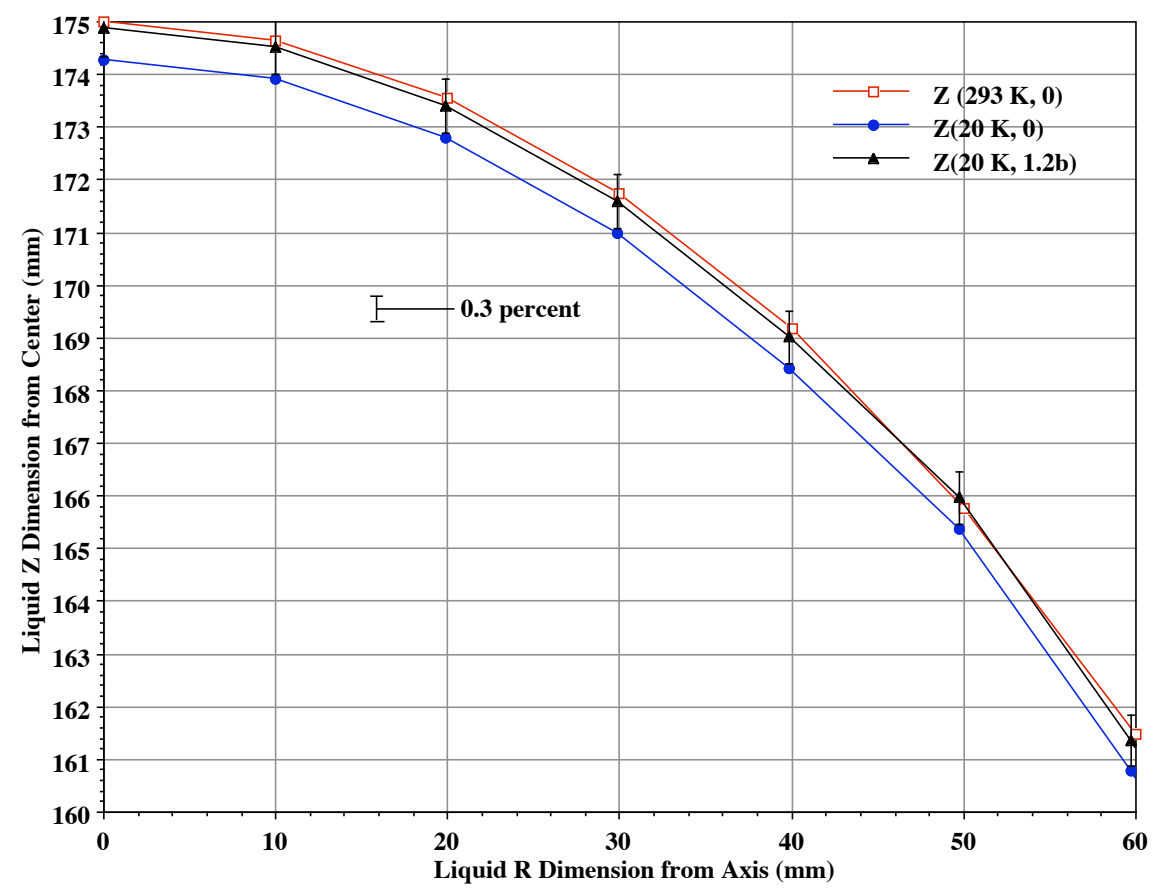

Figure 6. The $\mathrm{z}$ position of the inner absorber window (from the absorber center) from $\mathrm{R}=0$ to $\mathrm{R}=60 \mathrm{~mm}$ (the region where 75 to 80 percent of the muons will be entering the absorber). The cases are $\mathrm{T}=293 \mathrm{~K}, \mathrm{P}=0$;

$\mathrm{T}=20 \mathrm{~K}, \mathrm{P}=0$, and $\mathrm{T}=20 \mathrm{~K}, \mathrm{P}=1.2 \mathrm{bar}$. (Note: the error bars shown are for \pm 0.3 percent)

From Figure 6, it is clear that one can predict the liquid boundary for the absorber to better than \pm 0.3 percent, even if there is a 20 percent error in the calculations of the window deflection using ANSYS. Since ANSYS does a good job of calculating the burst pressure for the window (within 5 percent), it is unlikely that the error in the ANSYS calculations will be much more than 5 percent. It appears the liquid boundary for either the hydrogen or the helium absorber can be characterized to \pm 0.1 percent. It is much more likely that absorber characterization errors will be caused by variation in the absorber fluid density or not knowing the density because one doesn't know the fluid temperature in the absorber.

\section{Liquid Absorbers, Prediction of the Density of the Fluid in the Absorber}

The density of the fluid in the absorber is a function of its temperature and pressure. The density of liquid hydrogen on the saturated liquid line varies about 1 percent between $14 \mathrm{~K}$ and $15 \mathrm{~K}$ (near the para hydrogen triple point temperature). Between $20 \mathrm{~K}$ and $21 \mathrm{~K}$, the liquid hydrogen density changes about 1.7 percent along the saturated liquid line. When hydrogen is at $0.12 \mathrm{MPa}$ (1.2 bars), the variation with temperature is somewhat higher at lower temperatures. For liquid helium on the saturated liquid line, the density change is about 13.6 percent per degree at $4 \mathrm{~K}$. At $4.6 \mathrm{~K}$, the density variation goes up to 24 percent per degree. 
Figure 7 shows the variation of the density of liquid hydrogen over a range of temperatures between $14 \mathrm{~K}$ and $22 \mathrm{~K}$ at the saturation pressure for the liquid (see Figure 2) and at 1.2 bar (up to $20.8 \mathrm{~K}$ ) and saturated pressure above $20.8 \mathrm{~K}$. Figure 8 shows the density variation over a narrower temperature range from $16 \mathrm{~K}$ to $21 \mathrm{~K}$. The error bars in the figures correspond to a density variation of \pm 0.3 percent.

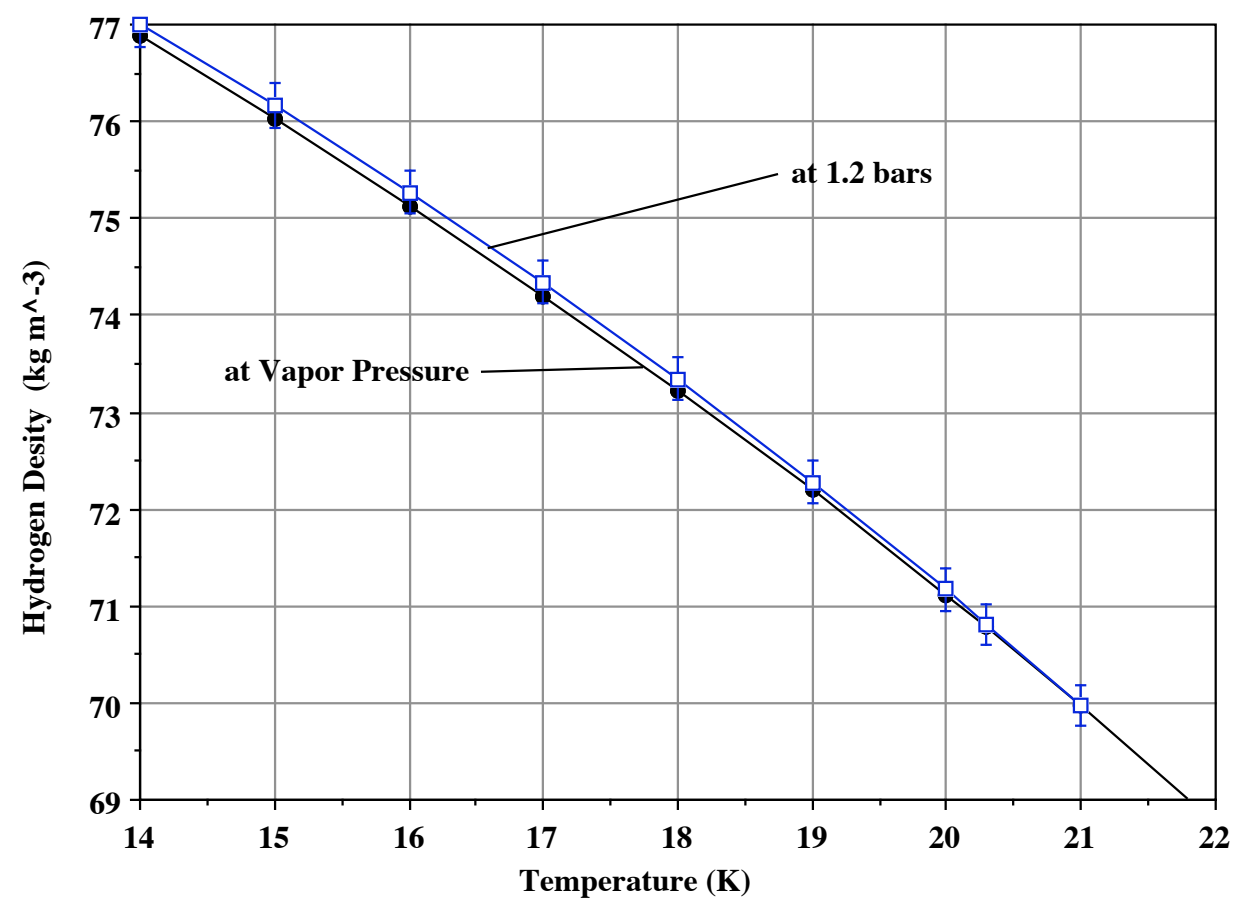

Figure 7. Liquid para hydrogen density from $14 \mathrm{~K}$ to $22 \mathrm{~K}$ at the vapor pressure of hydrogen and 1.2 bars [10]. (Note: the error bars represent an error of \pm 0.3 percent in the density.)

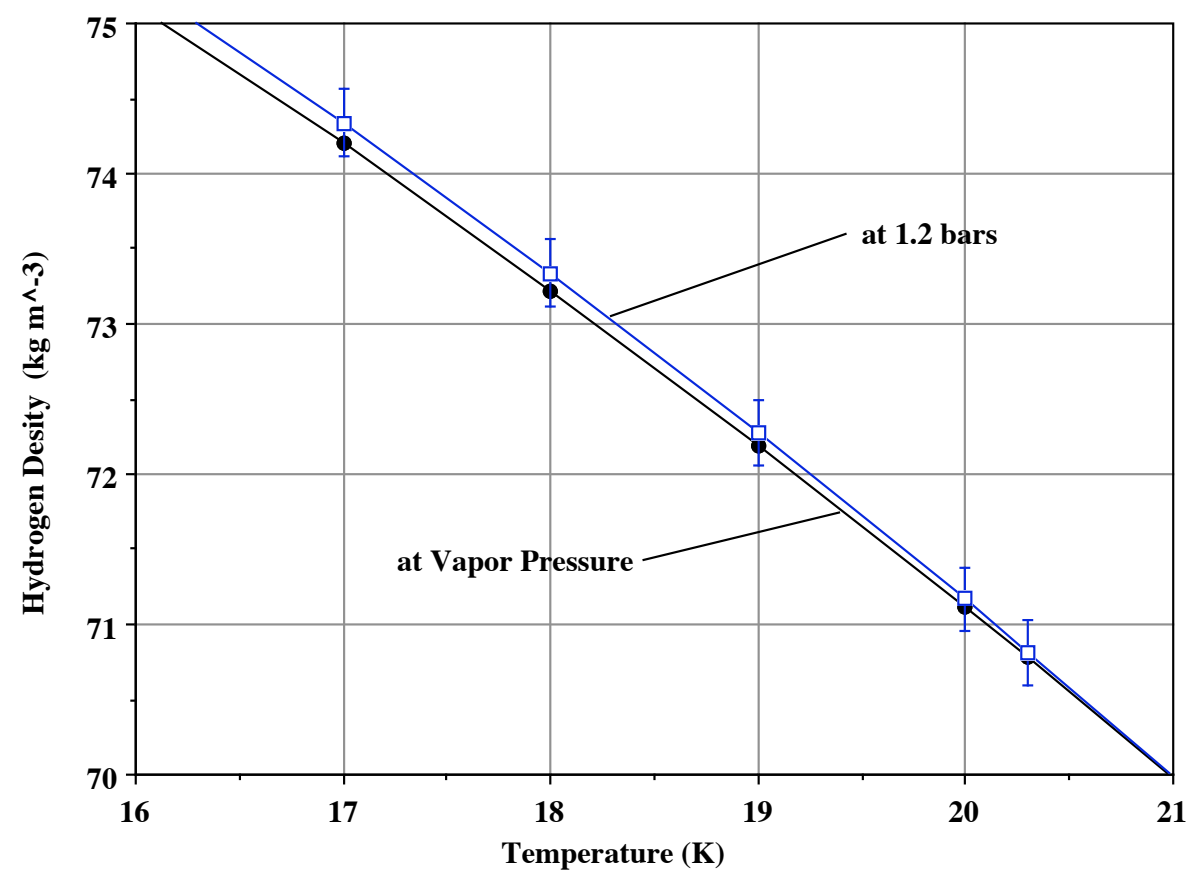

Figure 8. Liquid hydrogen density from $16 \mathrm{~K}$ to $21 \mathrm{~K}$ at the vapor pressure of hydrogen and 1.2 bars.

(Note: the error bars represent an error of \pm 0.3 percent in the density. 
Figure 9 shows the variation of the density of liquid helium over a range of temperatures between $3.6 \mathrm{~K}$ and $5.0 \mathrm{~K}$ at the saturation pressure for the liquid (see Figure 3). Figure 10 shows the density variation over a narrower temperature range from $4.2 \mathrm{~K}$ to $4.7 \mathrm{~K}$. The error bars in the figures correspond to a density variation of \pm 0.3 percent.

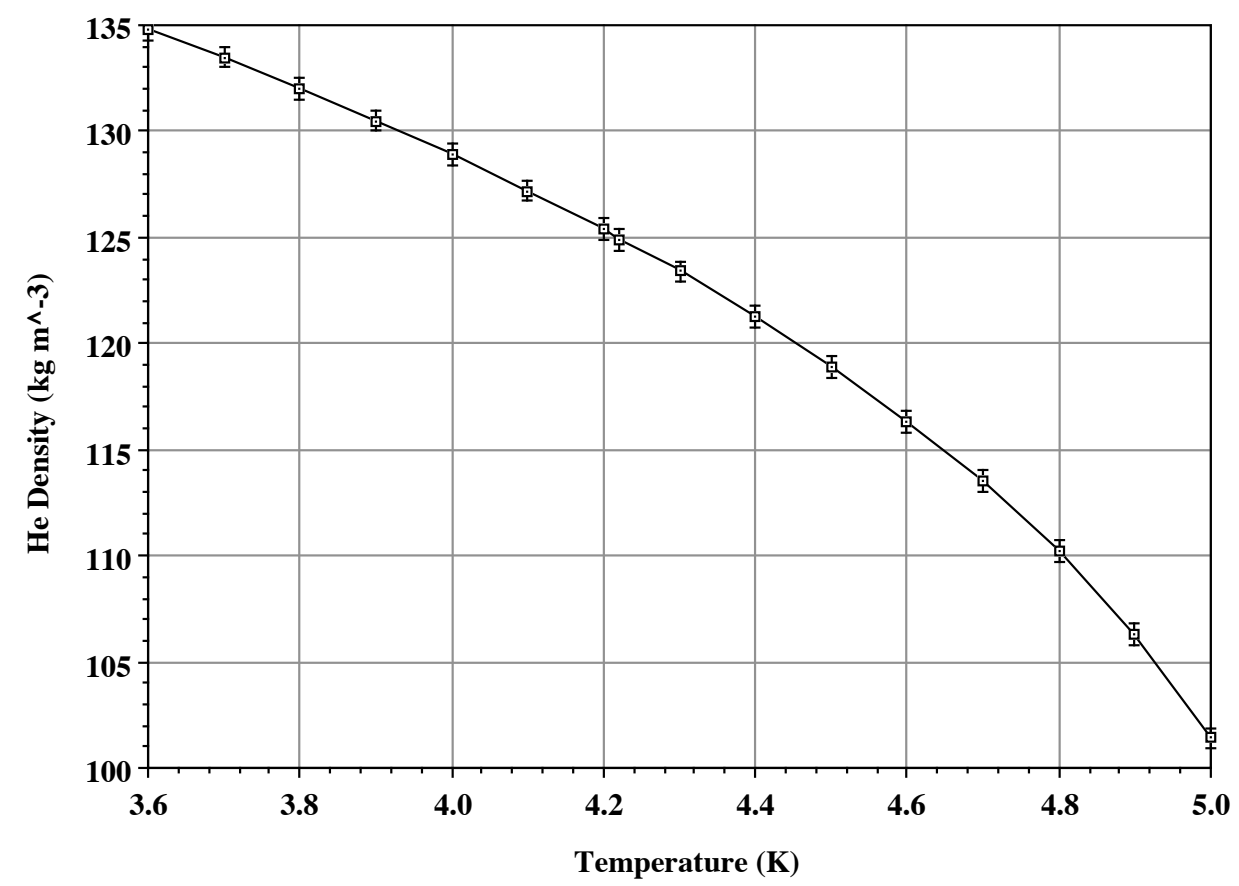

Figure 9. Liquid helium density from $3.6 \mathrm{~K}$ to $5.0 \mathrm{~K}$ at the vapor pressure of helium [11]. (Note: the error bars represent an error of 0.3 percent in the density.)

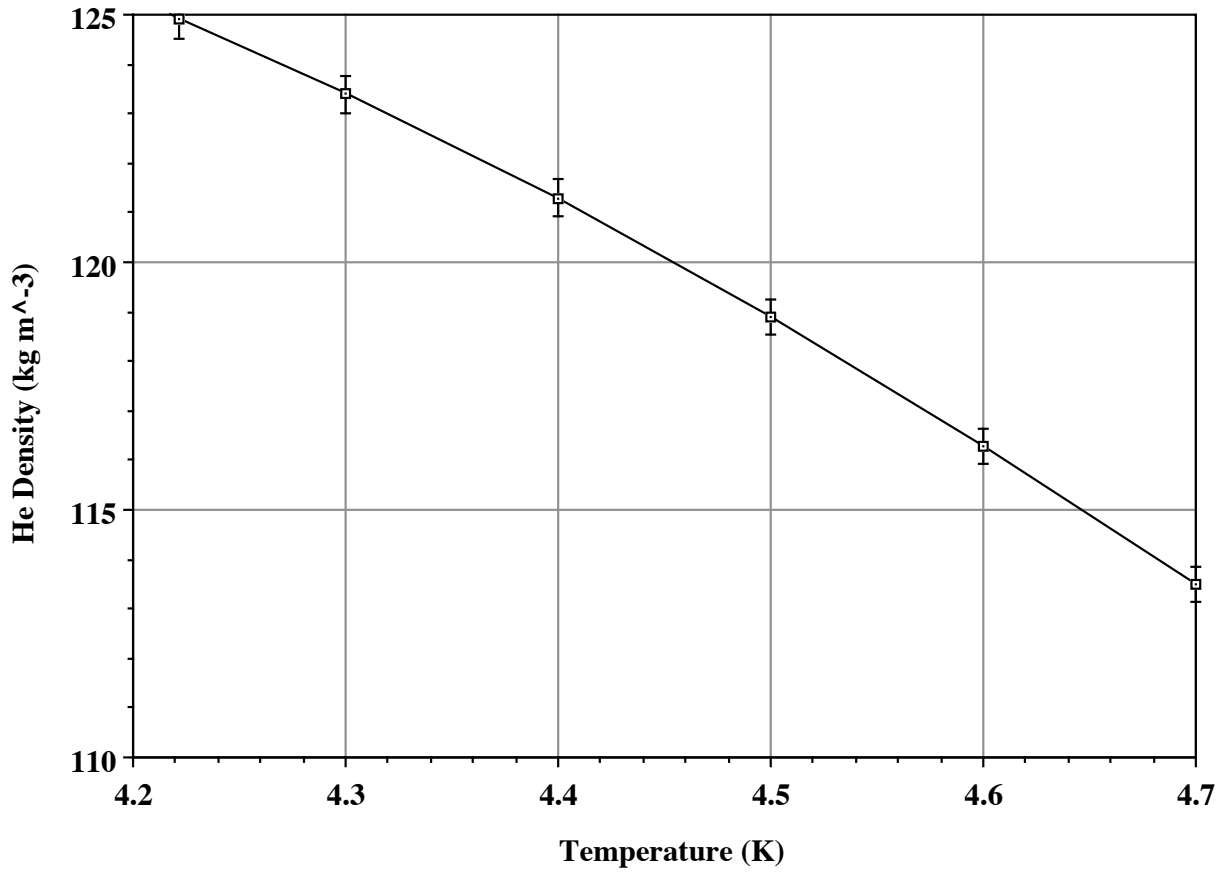

Figure 10. Liquid helium density from $4.2 \mathrm{~K}$ to $4.7 \mathrm{~K}$ at the vapor pressure of helium. (Note: the error bars represent an error of 0.3 percent in the density.) 
Using the thermometry proposed for MICE, one can measure the absolute temperature to about $0.1 \mathrm{~K}$. Perhaps one can do a little better to $0.05 \mathrm{~K}$ with well-calibrated sensors. The same sensors are capable of measuring quite small changes in temperature to say $10 \mathrm{mK}$, but the error in the absolute measurement will be much higher. When one looks at Figures 7 and 8, it is clear that one knows the density of the hydrogen to \pm 0.3 percent because one can measure the temperature to much better than $\pm 0.3 \mathrm{~K}$ (by at least a factor of three).

The other factor that controls density is the variation of the temperature across the absorber due to heating of the absorber from the outside and absorption of energy from the muon beam. There is virtually no heating of the liquid in the absorber due to the beam. If one applies heat to the absorber to control its temperature there can be temperature variations in the absorber. This means that heat must be applied to the second stage cold head in order to control the absorber temperature. The heat that goes into a well-insulated MICE absorber is of the order of 1 to 1.5 watts [13]. (A heat leak of $2 \mathrm{~W}$ is the worst case that one can stand over an indefinite period of time.) When the heat leak onto the absorber body is $1.5 \mathrm{~W}$, the maximum temperature variation in the absorber, when it is filled with liquid hydrogen is $0.3 \mathrm{~K}$, when heat is put into the hydrogen at the center of the absorber. This won't be happening because the heat will go into the body and the windows. Even with a heat leak into the absorber of $1.5 \mathrm{~W}$, the change in density within the absorber should be within the \pm 0.3 percent margin.

When liquid helium is in the absorber all bets are off to knowing the helium density to within \pm 0.3 percent. Even with the best thermometry, where one knows the absolute temperature to $\pm 0.05 \mathrm{~K}$, one might know the density to \pm 0.5 percent (at say $4.0 \mathrm{~K}$ ). If the heat leak into the absorber is high, so that the absorber temperature is $4.7 \mathrm{~K}$, the density variation will be much higher. With the best thermometry one might know the absorber density to \pm 0.75 percent. The variation of density in a helium absorber due to heating of the helium is expected to be worse than when the absorber contains liquid hydrogen.

\section{The Thin Windows and their Effect on Absorber Performance}

It is well understood that the thin windows affect the absorber length and the cooling efficiency of the liquid absorber. The effect of the windows varies with the radial position that the muon enters the absorber. The relative effect of the thin window material depends on the length of the muon track as it passes through the absorber. When the absorber is filled with liquid (either hydrogen or helium) the muons must pass through four thin windows. In most cases when a solid absorber is used, the muons pass through only one window (the fixed thin window in the bore of the AFC magnet). (If out-gassing of a plastic absorber, affects the quality of the vacuum in the RF cavities, a second window may be needed to protect the cavity from the plastic out-gassing. This second window is on the absorber vacuum door (see Figure 1).

The MICE absorber thin windows are designed not to have uniform thickness, unlike the torispherical windows originally designed for absorbers, which are much more uniform in thickness. The MICE windows are designed to be thin in the center region; where most of the muons (about 70 percent) enter and leave the absorber. The outer portion of the windows, where fewer muons enter and leave the absorber, is thicker than the center portion. The thickness of the MICE absorber thin windows as a function of window radius is shown in Figure 11. The thickness of the center portion of the window (to $r=60 \mathrm{~mm}$ ) is shown in Figure 12. 


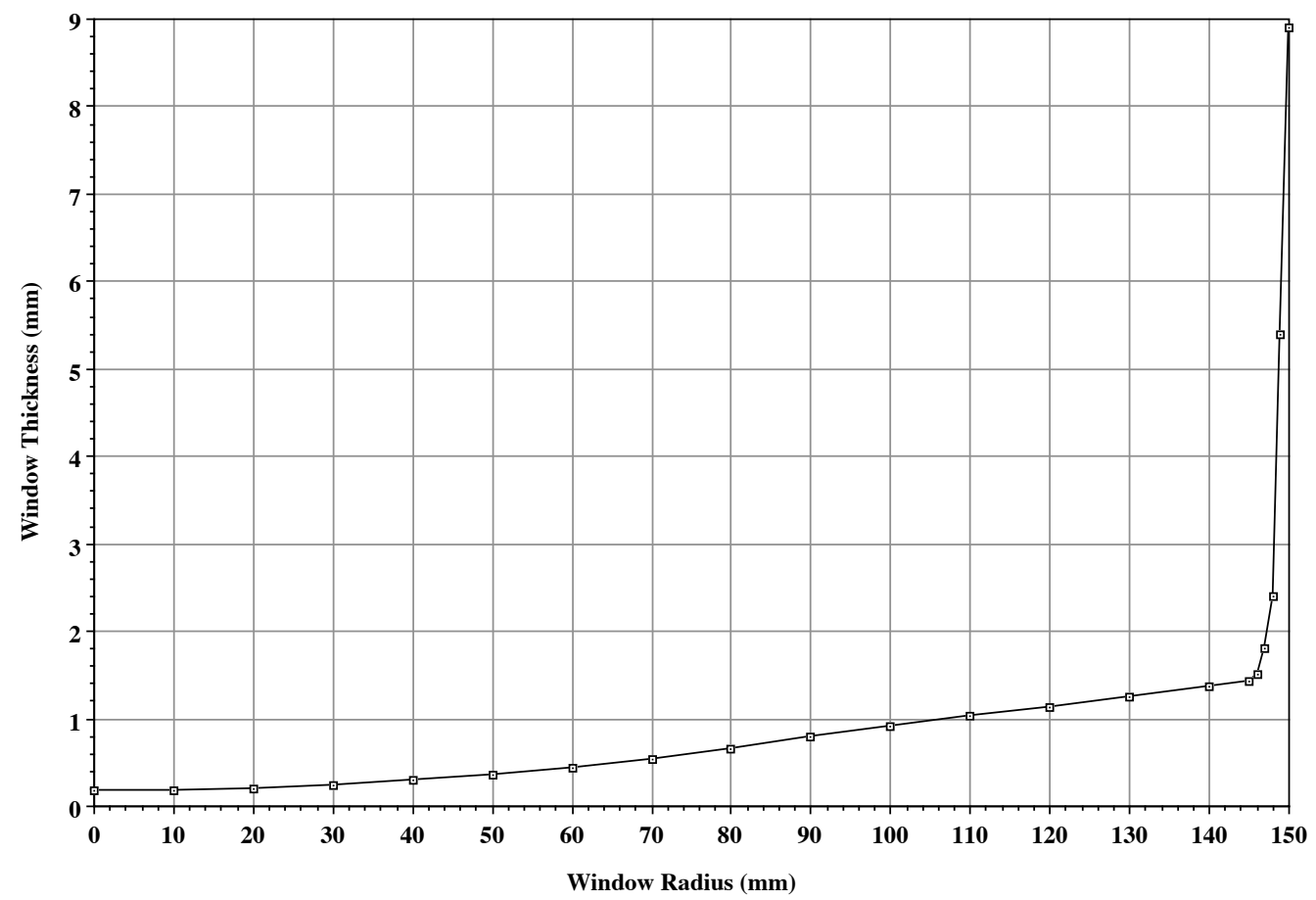

Figure 11. The Thickness of the Absorber Thin Window as a Function of the Window Radius

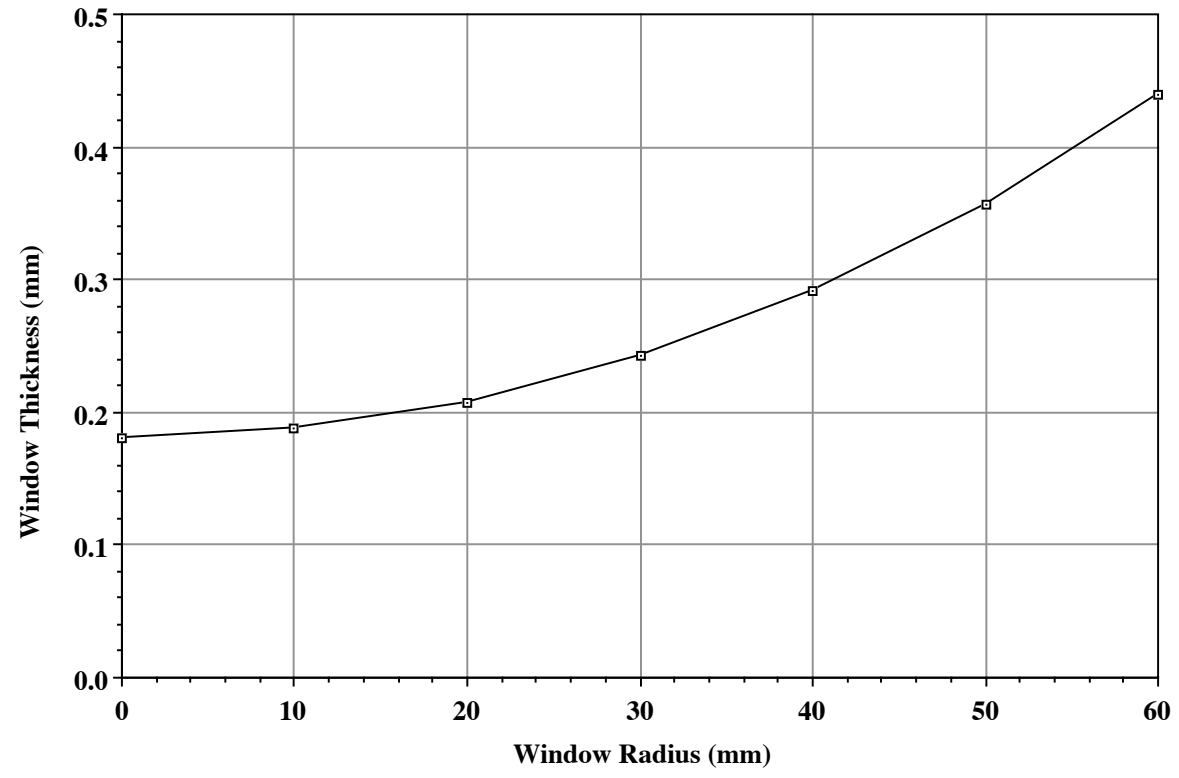

Figure 12. The Thickness of the Absorber Thin Window Center Section as a Function of the Window Radius

The four thin windows that are part of the liquid absorber system affect the muon cooling in two ways; 1) The four thin-windows add to the ionization cooling that provided by the liquid hydrogen or liquid helium. The cooling is increased where the windows are thicker. 2) The four thin-windows also increase scattering because they have a higher $Z$ than either the hydrogen or helium that is in the liquid absorber. As a result, the equilibrium cooling-factor for the absorber goes down compared to the liquid in the absorber alone. 
Figure 13 shows the total amount of energy that is taken from a muon as it passes through the MICE when it is filled with liquid hydrogen absorber as a function of the absorber radius. Figure 14 shows the total amount of energy that is taken from a muon as it passes through the MICE when it is filled with liquid helium absorber as a function of the absorber radius. Both Figure 13 and Figure 14 assume that the muon passes straight through the absorber along a track that is parallel to the absorber axis. If the muon track is curved, the path length is longer and the amount of muon cooling is increased.

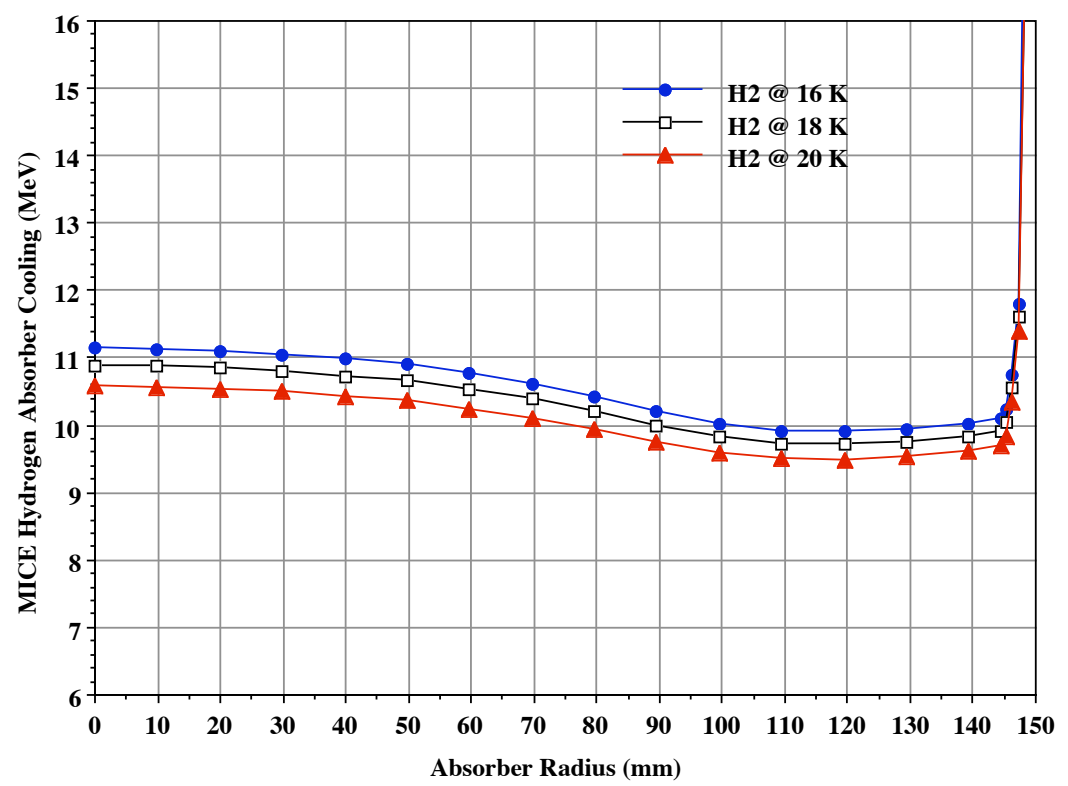

Figure 13. The Muon Energy Lost in the MICE Liquid Hydrogen Absorber as a Function of Absorber Radius and Temperature

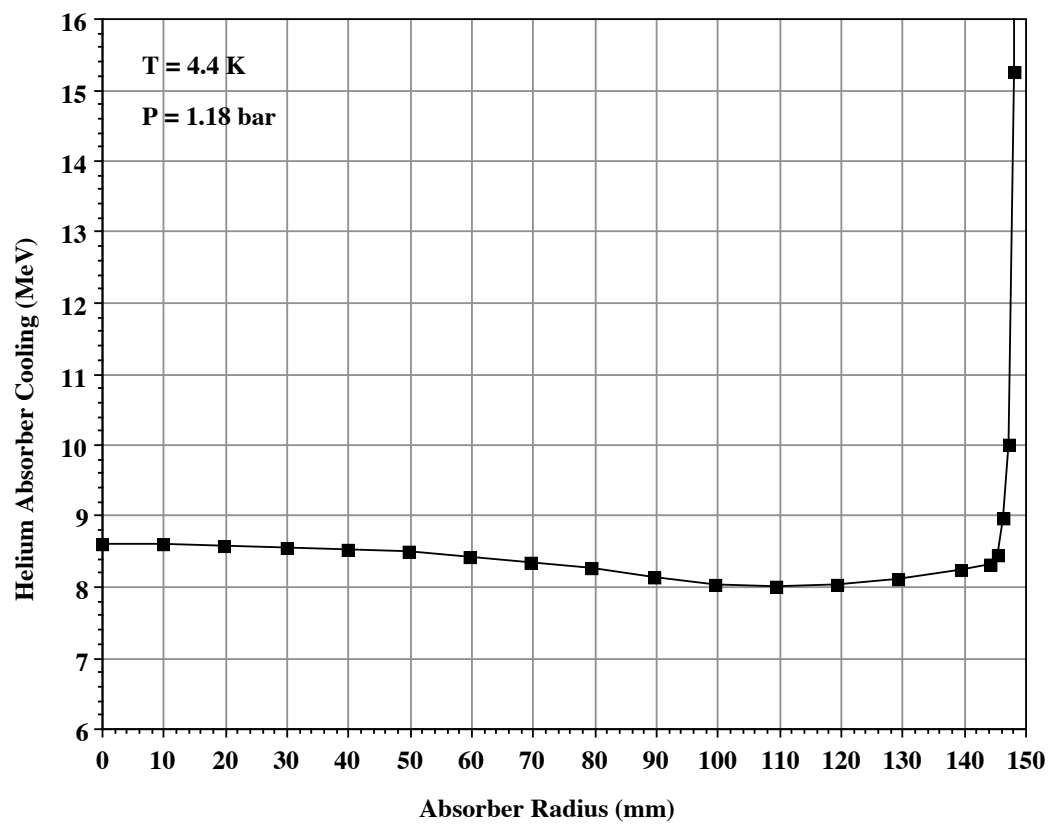

Figure 14. The Muon Energy Lost in the MICE Liquid Helium Absorber as a Function of Absorber Radius at $4.4 \mathrm{~K}$ 
From Figures 13 and 14, one can see that the increase thickness of the thin window helps increase muon cooling where there is shorter path through the liquid in the absorber. In the region of the absorber where most of the muon will pass through the absorber (from $r=0$ to $r=$ $60 \mathrm{~mm}$ ), the cooling is reasonably uniform. Cooling is increased at the edge of the window, but there are few muons to be cooled in the region. The down side of using the window to increase cooling on the outer portion of the absorber is the added scattering that the window introduces into the cooling process.

\section{Concluding Comments}

The relative performance of various liquid and solid absorbers for MICE is shown in Table 3. Cooling with solid absorbers is more uniform than cooling with liquid absorbers. The thin windows on the liquid absorber make the cooling different at different radii. Solid absorbers can be characterized to better than \pm 0.3 percent, except for lithium hydride. The problem with lithium hydride is its non-uniform density. Both lithium hydride and lithium must be in a can because they react with water in the air.

Table 3. A Comparison of the Cooling and Characterization of Various Absorber Materials

\begin{tabular}{|c|c|c|c|c|c|}
\hline Absorber Material & $\begin{array}{c}\text { Temperature } \\
\text { (K) }\end{array}$ & $\begin{array}{c}\text { Density } \\
\left(\mathrm{kg} \mathrm{m}^{-3}\right)\end{array}$ & $\begin{array}{c}\text { Length } \\
(\mathrm{mm})\end{array}$ & $\begin{array}{c}\text { Cooling } \\
\text { (MeV) }\end{array}$ & $\begin{array}{c}\text { Estimated } \\
\text { Accuracy } \\
\text { (\%) }\end{array}$ \\
\hline Liquid Hydrogen & $16 @ 1.2$ bar & 75.12 & $350^{*}$ & $11.14^{* *}$ & $\sim \pm 0.2$ \\
\hline Liquid Hydrogen & $18 @ 1.2$ bar & 73.22 & $350^{*}$ & $10.89^{* *}$ & $\sim \pm 0.2$ \\
\hline Liquid Hydrogen & $20 @ 1.2$ bar & 71.11 & $350^{*}$ & $10.57^{* *}$ & $\sim \pm 0.2$ \\
\hline Liquid Helium & 4.1 @ VP & 127.2 & $350^{*}$ & $8.68^{* *}$ & $\sim \pm 1.1^{\wedge \wedge \wedge}$ \\
\hline Liquid Helium & 4.4 @P & 121.3 & $350^{*}$ & $8.60^{* *}$ & $\sim \pm 1.3^{\wedge \wedge \wedge}$ \\
\hline Liquid Helium & $4.7 @$ VP & 113.5 & $350^{*}$ & $8.05^{* *}$ & $\sim \pm 1.5^{\wedge \wedge}$ \\
\hline Lithium Hydride & 293 & $\sim 780$ & $\sim 68^{\wedge}$ & $\sim 10$ & $\sim \pm 1.0$ \\
\hline Lithium & 293 & 534 & 113.5 & 10 & $\sim \pm 0.3$ \\
\hline Beryllium & 293 & 1848 & 33.61 & 10 & $\sim \pm 0.07$ \\
\hline Polystyrene $(\mathrm{CH})^{\mathrm{K}}$ & 293 & 1032 & 46.36 & 10 & $\sim \pm 0.05$ \\
\hline Carbon $($ graphite) & 293 & 1800 to 2300 & 24 to $31^{\wedge \wedge}$ & 10 & $\sim \pm 0.3$ \\
\hline 1100-Aluminum & 293 & 2699 & 22.87 & 10 & $\sim \pm 0.05$ \\
\hline
\end{tabular}

* This length is the liquid length inside of the windows at the center of the absorber $(\mathrm{R}=0)$.

** This is the amount of cooling along a track through the center of the absorber $(\mathrm{R}=0)$.

$\wedge \quad$ The density is highly variable for solid lithium hydride.

$\wedge \wedge$ Graphite can occur in several forms. The density of a particular sample is quite uniform.

$\wedge \wedge \wedge$ The density is not known because it is difficult to measure the temperature accurately to $\pm 25 \mathrm{mK}$.

The MICE liquid absorber dimensions can be known to better than \pm 0.1 percent as long as one knows the temperature and pressure in the absorber. Even if one doesn't know the pressure in the absorber, its dimensions are known to better than \pm 0.3 percent. The characterization of the liquid absorber depends on how well one knows the density of the fluid in the absorber. Because one can measure the temperature of the hydrogen absorber to better than $\pm 0.1 \mathrm{~K}$, one knows the density to better \pm 0.3 percent. Because it is difficult to measure the temperature of the helium to better than $\pm 25 \mathrm{mK}$, a helium absorber cannot be characterized to \pm 1 percent. 
The shape of the liquid absorber thin windows and the thickness of the windows have a strong effect on the cooling. The four thin windows add about $0.31 \mathrm{MeV}$ to the cooling at the center of the absorber. At $\mathrm{r}=60 \mathrm{~mm}$, the four windows add $0.77 \mathrm{MeV}$ to the liquid cooling at that radius. The variable thickness of the windows means that the cooling is more uniform across the absorber. The down side of the window material is that it is a source of extra scattering. Fortunately, seventy-five percent of the muon enter and exit the absorber at a radius less than $60 \mathrm{~mm}$.

\section{Acknowledgements}

This work was supported by the Oxford University Physics Department and the Particle Physics and Astronomy Research Council of the United Kingdom. This work was also supported by the Office of Science, United States Department of Energy, under DOE contract DE-AC02-05CH11231. DOE funding for the US Neutrino Factory and Muon Collider Collaboration is gratefully acknowledged.

\section{References}

[1] S. Ozaki, R. B. Palmer, M. S. Zisman and J. Gallardo Editors, "Feasibility Study II of a Muon Based Neutrino Source,” BNL-52623, June 2001

[2] D. M. Kaplan, "MuSat and MICE Experimental Verification of Ionization Cooling Techniques," presented at the First International Neutrino Factory Summer Institute, Cosner's House, Abingdon UK 29 June 2003

[3] "A Proposal to the Rutherford Appleton Laboratory, an International Muon Ionization Cooling Experiment (MICE)," proposed by the MICE Collaboration, 15 December 2002

[4] D. E. Baynham, T. Bradshaw, et al., "A Liquid Absorber for MICE," Advances in Cryogenic Engineering 51, AIP Press, Melville NY, (2005)

[5] G. Gregoire, G. Ryckewaert, L. Chevalier, et al, "MICE and International Muon Ionization Cooling Experiment Technical Reference Document," http://hep04.phys.itt.edu/cooldemo

[6] Handbook of Chemistry and Physics 36, pp 1761 to 1763 Chemical Rubber Publishing Company, Cleveland OH, (1955)

[7] Handbook of Chemistry and Physics 58, p B-438, CRC Press Inc, Cleveland OH, (1977)

[8] "Review of Particle Properties," Reviews of Modern Physics 48, Number 2, Part II, April 1976

[9] Handbook of Materials for Superconducting Machinery, Metal and Ceramics Information Center, MIC-MB-04, National Bureau of Standards, Jan. 1977

[10] Victor J. Johnson Ed., A Compendium of the Properties of Materials at Cryogenic Temperature, Pergamon Press, New York (1961)

[11] V. D Arp and R. D. McCarthy, "Thermophysical Properties of Helium-4 from 0.8 to $1500 \mathrm{~K}$ with Pressures to $2000 \mathrm{MPa}$," NIST Technical Note 1334, (1989)

[12] W. Lau, S. Q. Yang, and M. A. Green, "The Development of a 6061 Window for the MICE Liquid Absorber," Advances in Cryogenic Engineering 51, AIP Press, Melville NY, (2005)

[13] D. E. Baynham, T. Bradshaw, M. A. Green, et al, "Cooling of the MICE Liquid Absorber Using a Small Cooler," Advances in Cryogenic Engineering 51, AIP Press, Melville NY, (2005) 